Roland Roth/Dieter Rucht (Hrsg.)

Jugendkulturen, Politik und Protest 
Roland Roth/Dieter Rucht (Hrsg.)

\section{Jugendkulturen, Politik und Protest}

Vom Widerstand zum Kommerz?

Leske + Budrich, Opladen 2000 
Die Deutsche Bibliothek - CIP-Einheitsaufnahme Ein Titeldatensatz für diese Publikation ist bei Der Deutschen Bibliothek erhältlich.

ISBN 978-3-322-99914-6 ISBN 978-3-322-99913-9 (eBook)

DOI 10.1007/978-3-322-99913-9

Gedruckt auf säurefreiem und alterungsbeständigem Papier.

(C) 2000 Leske + Budrich, Opladen

Das Werk einschließlich aller seiner Teile ist urheberrechtlich geschützt. Jede Verwertung außerhalb der engen Grenzen des Urheberrechtsgesetzes ist ohne Zustimmung des Verlages unzulässig und strafbar. Das gilt insbesondere für Vervielfältigungen, Übersetzungen, Mikroverfilmungen und die Einspeicherung und Verarbeitung in elektronischen Systemen. 


\section{Inhalt}

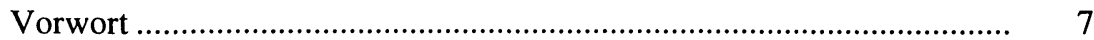

Roland Roth und Dieter Rucht

Jugendliche heute: Hoffnungsträger im Zukunftsloch?

\section{Teil I:}

Jugend, Kultur, Politik und Protest: Konzeptionelle und

historische Annäherungen

Hartmut M. Griese

,Jugend(sub)kultur(en)‘ : Facetten, Probleme und Diskurse

Rainer Paris

Schwacher Dissens. Kultureller und politischer Protest

Titus Simon

Straßenjugendkulturen im Wandel

Volker Böge

Wie das Unpolitische politisch wird. Jugendbanden in Hamburg-Eimsbüttel in den 40er und 50er Jahren

\section{Teil II: Gegenentwürfe}

Karin Schittenhelm

Dissens, Distinktion und Gegenentwürfe in sozio-kulturellen Milieus junger Frauen

Dieter Rink

Der Traum ist aus? Hausbesetzer in Leipzig-Connewitz in den 90er Jahren 
Sebastian Haunss

Das Innere sozialer Bewegungen. Strukturelle Konfliktlinien

basisdemokratischer Bewegungsorganisationen

Heiko Geiling

Punk als politische Provokation: Mit den Chaos-Tagen in Hannover

zur Politik des, gesunden Volksempfindens“

Flemming Mikkelsen und Rene Elley Karpantschof

Hausbesetzungen, Jugend und sozialer Protest. Jugendbewegungen

in Dänemark von 1965-1995

Markus Mathyl

Hammer und Sichel in der Fahne Hitlers. Das Entstehen einer

nationalistischen Gegenkultur im Postperestrojka-Rußland

\section{Teil III: Abkehr von der Politik?}

Arnd-Michael Nohl

Von der praktischen Widerständigkeit zum Generationsmilieu:

Adoleszenz und Migration in einer Breakdance-Gruppe

Jean Weinfeld

HipHop - Licht und Schatten einer Jugendkulturbewegung

Dietmar Loch

Jugendprotest in französischen Vorstädten. Von der Gewalt zur

Integration durch Anerkennungskonflikte?

Dieter Rucht und Roland Roth

Weder Rebellion nach Anpassung: Jugendproteste in der

Bundesrepublik 1950-1994

Autorinnen und Autoren 305 


\section{Vorwort}

Die meisten Beiträge dieses Bandes gehen auf eine Tagung des Arbeitskreises „Soziale Bewegungen“ in der Deutschen Vereinigung für Politische Wissenschaft zurück, die im September 1998 am Wissenschaftszentrum Berlin stattfand. Daraus ergeben sich einige der gemeinsamen Bezugspunkte der Aufsätze. Wir waren bemüht, ein möglichst breites Spektrum von Forschungsansätzen zu versammeln. Jugendsoziologie, historische Forschung, Gewaltund Rechtsradikalismusstudien, Stadtforschung, Kultur- und Sozialstrukturanalysen u.a.m sind heute gleichermaßen gefragt, wenn es darum geht, die Lebensentwürfe von Jugendlichen, ihre Lebensstile, Milieus, Kulturen und Subkulturen sowie ihre Widerständigkeiten zu beschreiben und zu verstehen. Der Versuch, die Grenzen zwischen diesen wissenschaftlichen Disziplinen zu überwinden, und die Absicht, auch transnationale Entwicklungen durch Beiträge aus anderen Ländern sichtbar zu machen, hat von vornherein den Verzicht auf eine möglichst umfassende Bestandsaufnahme zum Themenfeld dieses Bandes bedeutet. Schon ein Kompendium der aktuellen Musikstile oder gar der existierenden Jugendsubkulturen in der Bundesrepublik hätte den Rahmen dieses Bandes gesprengt. Wir hoffen jedoch, dass die teils systematisch, teils exemplarisch ausgerichteten Beiträge dieses Bandes neuen Schwung in die Debatte über Jugendliche, Politik, Kultur und Protest bringen. Dies scheint uns um so notwendiger, je stärker die öffentliche Diskussion von Negativbildern über Jugendliche beherrscht wird, die dazu taugen, den Anteil der Erwachsenengeneration an der zum Teil bedrückenden Lage von Jugendlichen zu verdecken. Gegen solche Verdrängungen anzugehen und für die Botschaften von Jugendkulturen und -protesten zu sensibilisieren, scheint uns engagierter wissenschaftlicher Mühe wert. Wir danken den TeilnehmerInnen der Tagung und den AutorInnen dieses Bandes für ihre Mitarbeit. 